\title{
STABILITY INDICATING AND COST-EFFECTIVE ANALYTICAL METHOD DEVELOPMENT AND VALIDATION OF SOTORASIB BY USING RP-HPLC
}

\section{SUBBA RAO YARLAGADDA ${ }^{1}$, SUBBA RAO MANNAM ${ }^{2 *}$, BABY PADMINI JAMPANI ${ }^{3^{*}}$}

${ }^{1}$ Research Scholars, Department of Chemistry, Acharya Nagarjuna University, Guntur-522510, AP, India, ${ }^{* 2}$ Department of Chemistry, Acharya Nagarjuna University, Guntur-522510, AP, India, 3Department of Chemistry, Sri Vasavi Institute of Engineering and Technology, Nandamuru, Pedana, AP, India.

Email: subbaraomanam9@gmail.com

Received: 06 Jul 2021, Revised and Accepted: 05 Aug 2021

\section{ABSTRACT}

Objective: The current investigation was pointed at developing and progressively validating novel, simple, responsive and stable RP-HPLC method for the measurement of active pharmaceutical ingredient of Sotorasib.

Methods: A simple, selective, validated and well-defined stability that shows isocratic RP-HPLC methodology for the quantitative determination of Sotorasib. The chromatographic strategy utilized symmetry $\mathrm{C}_{18}$ column of dimensions $150 \mathrm{x} 4.6 \mathrm{~mm}, 3.5 \mu$, using isocratic elution with a mobile phase of acetonitrile and $0.1 \%$ orthophosphoric acid (70:30). A flow rate of $1 \mathrm{ml} / \mathrm{min}$ and a detector wavelength of $221 \mathrm{~nm}$ utilizing the PDA detector were given in the instrumental settings. Validation of the proposed method was carried out according to an international conference on harmonization (ICH) guidelines.

Results: LOD and LOQ for the active ingredient were established with respect to test concentration. The calibration chart plotted was linear with a regression coefficient of $\mathrm{R}^{2}>0.999$, means the linearity was within the limit. Recovery, specificity, linearity, accuracy, robustness, ruggedness were determined as a part of method validation and the results were found to be within the acceptable range.

Conclusion: The proposed method to be fast, simple, feasible and affordable in assay condition. During stability tests, it can be used for routine analysis of the selected drug.

Keywords: Sotorasib, RP-HPLC, Development, Validation, Stability

(C) 2021 The Authors. Published by Innovare Academic Sciences Pvt Ltd. This is an open access article under the CC BY license (https://creativecommons.org/licenses/by/4.0/) DOI: https://dx.doi.org/10.22159/ijap.2021v13i5.42659. Journal homepage: https://innovareacademics.in/journals/index.php/ijap

\section{INTRODUCTION}

Sotorasib, sold under the brand name Lumakras is an anti-cancer medication [1, 2] used to treat non-small-cell lung cancer (NSCLC) $[3,4]$. It targets a specific mutation, G12C, in the protein KRAS [5, 6] , which is responsible for various forms of cancer [7]. The most common side effects include diarrhea [8], musculoskeletal pain [9], nausea [10], fatigue [11, 12], and liver damage [13] and cough [14]. Sotorasib is an inhibitor of the RAS GTPase [15, 16] family. Sotorasib is the first approved targeted therapy for tumors [17] with any KRAS mutation, which accounts for approximately 25\% of mutations in non-small cell lung cancers. KRAS G12C mutations represent about $13 \%$ of mutations in non-small cell lung cancers. Because the G12C KRAS mutation is relatively common in some cancer types, $14 \%$ of non-small-cell lung cancer adenocarcinoma [18] patients and $5 \%$ of colorectal cancer $[19,20]$ patients, and sotorasib is the first drug candidate to target this mutation, there have been high expectations for the drug. The Food and Drug Administration [21] has granted a fast track designation to sotorasib for the treatment of metastatic non-small-cell lung carcinoma with the G12C KRAS mutation. Researchers evaluated the efficacy of sotorasib in a study of 124 participants with locally advanced or metastatic KRAS G12C-mutated non-small cell lung cancer with disease progression after receiving an immune checkpoint inhibitor [22, 23] and/or platinum-based chemotherapy $[24,25]$. The major outcomes measured were objective response rate (proportion of participants whose tumor is destroyed or reduced) and duration of response. The objective response rate was $36 \%$ and $58 \%$ of those participants had a duration of response of six months or longer. The aim of the study is to estimate the pharma ingredient Sotorasib by using RP-HPLC.

\section{MATERIALS AND METHODS}

\section{Chemicals}

Acetonitrile (HPLC-grade), orthophosphoric acid, water was purchased from Merck India Ltd, Mumbai, India. API of Sotorasib standard was procured from Glenmark, Mumbai.

\section{The instrumentation}

Waters alliance liquid chromatography (model 2695) was monitored with empower 2.0 data handling system and a detector of photo diode array (model 2998) was used for this study [26].<smiles>C=CC(=O)N1CCN(c2nc(=O)n(-c3c(C)ccnc3C(C)C)c3nc(-c4c(O)cccc4F)c(F)cc23)[C@@H](C)C1</smiles>

Fig. 1: Structure of sotorasib

\begin{abstract}
Method optimization
To optimize the chromatographic conditions, different ratios of phosphate buffer and the acetonitrile in the mobile phase with isocratic mode were tested. However, the mobile phase composition was modified at each trial to enhance the resolution and also to achieve acceptable retention time. Finally $0.1 \%$ orthophosphoric acid buffer and acetonitrile with isocractic elution was selected because it results in a greater response of active pharmacy ingredient. During the optimization of the method various stationary phases such as $\mathrm{C}_{8}, \mathrm{C}_{18}$ and amino, phenyl columns were tested. From these trials the peak shape was relatively good with Symmetry $C_{18}$ column of $150 \times 4.6 \mathrm{~mm}, 3.5 \mu$ with a PDA detector. The mobile phase flow rate has been done at $221 \mathrm{~nm}$ in order to obtain enough sensitivity. By using above conditions we get retention time of Sotorasib was about $2.271 \mathrm{~min}$ with a tailing factor of 1.01 . The
\end{abstract}


number of theoretical plates for Sotorasib was 4526, which indicate the column's successful output the \% RSD for six replicate injections was around $0.59 \%$, the proposed approach suggests that it is extremely precise. According to ICH guidelines, the method established was validated.

Till today there are no HPLC methods were reported in the literature, but only few methods are developed in the analysis of Sotorasib. Hence we developed method for the quantification of Sotorasib. The developed HPLC method was utilized for the estimation of the drug by in vitro method.

\section{Validation procedure}

The analytical parameters such as system suitability, precision, specificity, accuracy, linearity, robustness, LOD, LOQ, forced degradation and stability were validated according to ICH Q2 (R1) guidelines [27-29].

\section{Preparation of buffer}

$1 \mathrm{ml}$ of orthophosphoric acid (OPA) was dissolved in 1 litre of HPLC grade water and filtered through $0.45 \mu$ filter paper.

\section{Chromatographic conditions}

The HPLC analysis was performed on a reverse-phase HPLC system with isocratic elution mode using a mobile phase of acetonitrile and $0.1 \%$ OPA and Symmetry $C_{18}(150 \times 4.6 \mathrm{~mm}, 3.5 \mu)$ column with a flow rate of $1 \mathrm{ml} / \mathrm{min}$.

\section{Diluent}

Mobile phase was used as a diluent.

\section{Preparation of the standard stock solution}

For standard stock solution preparation, $70 \mathrm{ml}$ of diluents was added to $100 \mathrm{mg}$ of Sotorasib (taken in a $100 \mathrm{ml}$ volumetric flask) and sonicated for $10 \mathrm{~min}$ to fully dissolve the contents and then makeup to the mark with diluent.

\section{Preparation of Standard solution}

$1 \mathrm{ml}$ of solution is drawn from the above normal stock solution into a $10 \mathrm{ml}$ volumetric flask and diluted up to the level.

\section{RESULTS AND DISCUSSION}

The main analytical challenge during the development of a new method was to separate active Pharma ingredients. In order to provide good performance, the chromatographic conditions were optimized.

\section{System suitability}

In System suitability injecting standard solution and reported USP tailing and plate count values are tabulated in table 1 and the standard chromatogram was shown in fig. 2 [30].

Table 1: Results of system suitability

\begin{tabular}{lll}
\hline $\begin{array}{l}\text { System suitability } \\
\text { parameter }\end{array}$ & $\begin{array}{l}\text { Acceptance } \\
\text { criteria }\end{array}$ & Sotorasib \\
\hline USP Plate Count & NLT 2000 & 4526 \\
USP Tailing & NMT 2.0 & 1.01 \\
USP Resolution & NLT 2.0 & - \\
$\%$ RSD & NMT 2.0 & 0.59 \\
\hline
\end{tabular}

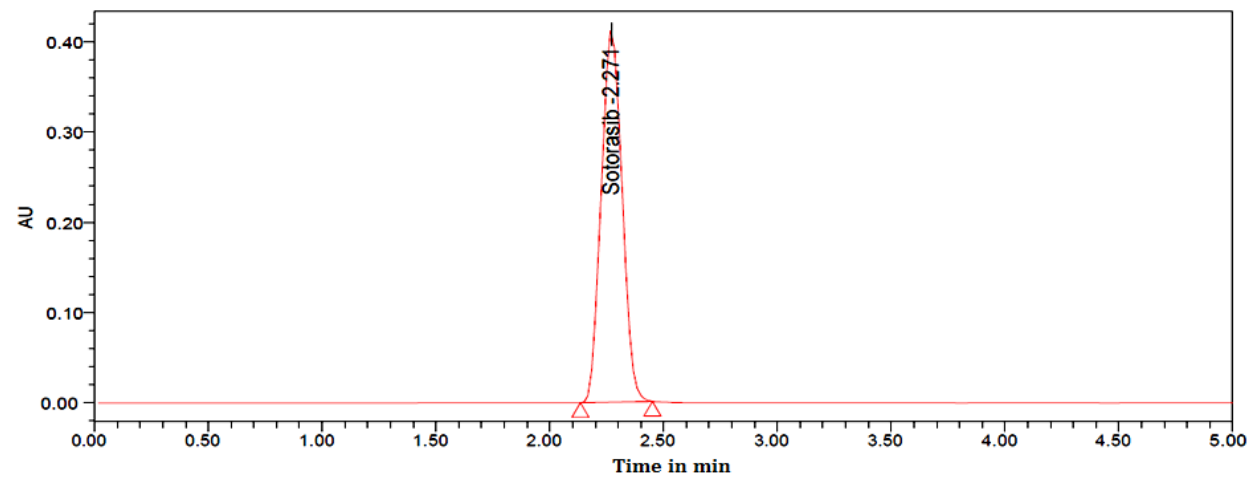

Fig. 2: Chromatogram of standard

\section{Specificity}

In this test method placebo and standard solutions were analyzed individually to examine the interference. The below fig. shows that the active ingredients were well separated from blank and their excipients and there was no interference of placebo with the principal peak. Hence the method is specific [31].

\section{Linearity}

The area of the linearity peak versus different concentrations has been evaluated for sotorasib, as 10, 25, 50, 100, 125, 150 percent dilutions [32], respectively. Linearity was performed in the range of $10-150 \mu \mathrm{g} / \mathrm{ml}$ of sotorasib. The correlation coefficient achieved greater than 0.999 for all.

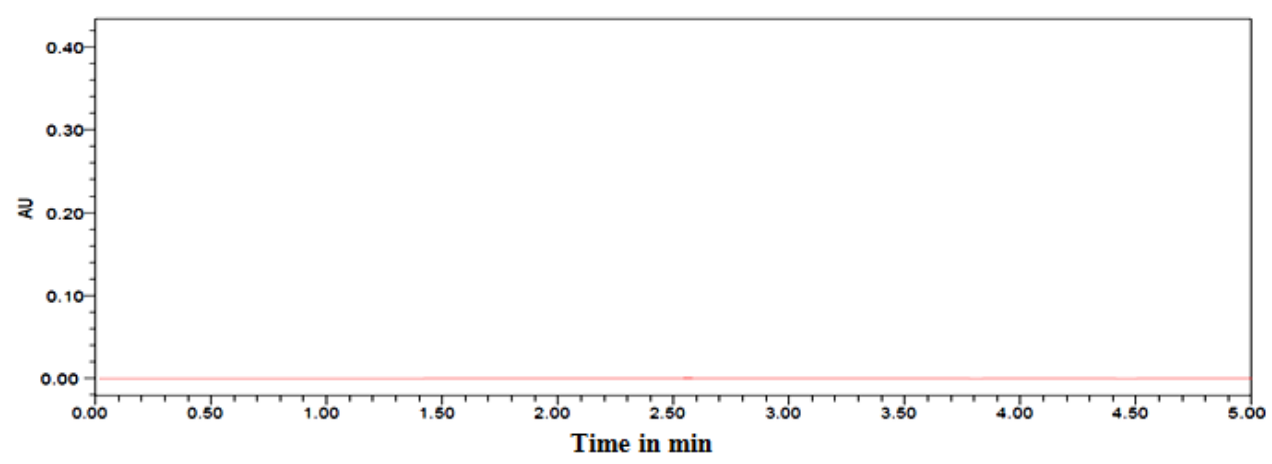

Fig. 3: Chromatogram of blank 
Table 2: Linearity of sotorasib

\begin{tabular}{lll}
\hline S. No. & Conc $\boldsymbol{\mu g} / \mathbf{m l}$ & Sotorasib area count \\
\hline 1 & 10.00 & 326971 \\
2 & 25.00 & 731459 \\
3 & 50.00 & 1347935 \\
4 & 100.00 & 2619390 \\
5 & 125.00 & 3263458 \\
6 & 150.00 & 3946340 \\
Correl coef & & 0.99982 \\
Slope & & 25884.83 \\
intercept & & 46933.12 \\
\hline
\end{tabular}

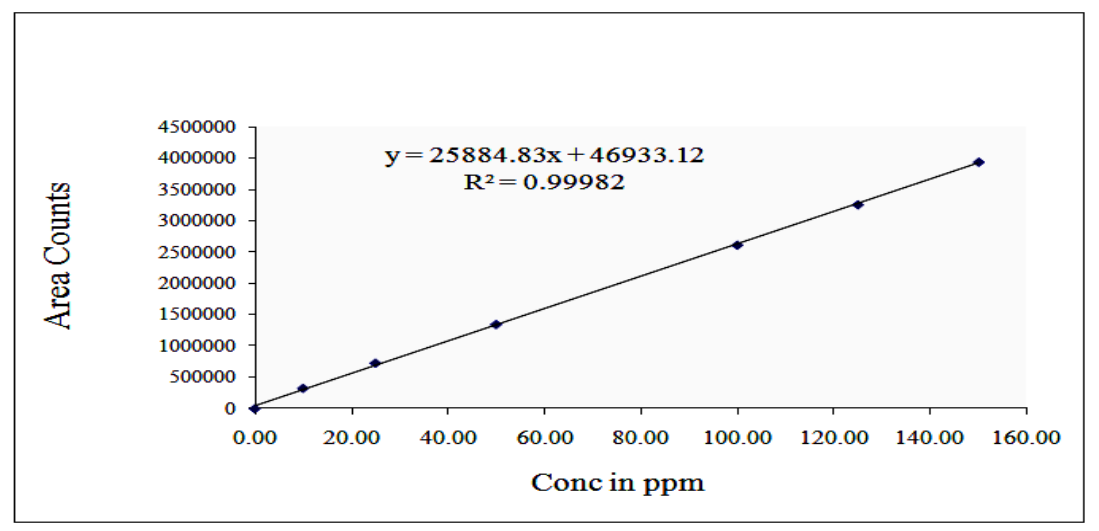

Fig. 4: Calibration plot of sotorasib

\section{Accuracy}

Three kinds of concentration levels of 50,100, and 150 percent at a specified limit were used in this process to assess the accuracy of this particular method. The developed method was found to be highly accurate and reliable. The recovery percentages, ranging from 99.38 to 99.71, were discovered. The results are given in table 3 [33].

\section{Precision}

In method precision study, prepare six different standard solutions in the concentration of sotorasib $(100 \mu \mathrm{g} / \mathrm{ml}))$ are injected into HPLC system. Sotorasib \%assay was found to be in the range of 99.3101.2. Peak areas were calculated, which were used to calculate mean, SD and \%RSD values. These results are given below table 4 .

Table 3: Results of accuracy

\begin{tabular}{llll}
\hline S. No. & \% Level & Sotorasib \% recovery* & Average \% recovery \\
\hline 1 & 50 & 99.7 & 100.5 \\
& & 101.3 & \\
2 & \multirow{2}{*}{100} & 100.5 & 100.3 \\
& & 100.2 & \\
3 & \multirow{2}{*}{150} & 100.0 & 100.6 \\
& & 100.7 & \\
\hline
\end{tabular}

*Mean+SD, n=3

Table 4: Intraday precision results of sotorasib

\begin{tabular}{llll}
\hline Sotorasib & & & \\
\hline S. No. & Conc. $(\boldsymbol{\mu g} / \mathbf{m l})$ & Area counts & assay as is \\
\hline 1 & 100 & 2632418 & 99.3 \\
2 & & 2601582 & 99.8 \\
3 & & 2614570 & 100.3 \\
4 & & 2628269 & 99.9 \\
5 & & 2617321 & 101.2 \\
6 & 0.66 & 2651651 & \\
$\%$ RSD & 100.2 & & \\
mean & 0.656 & & \\
SD & & &
\end{tabular}




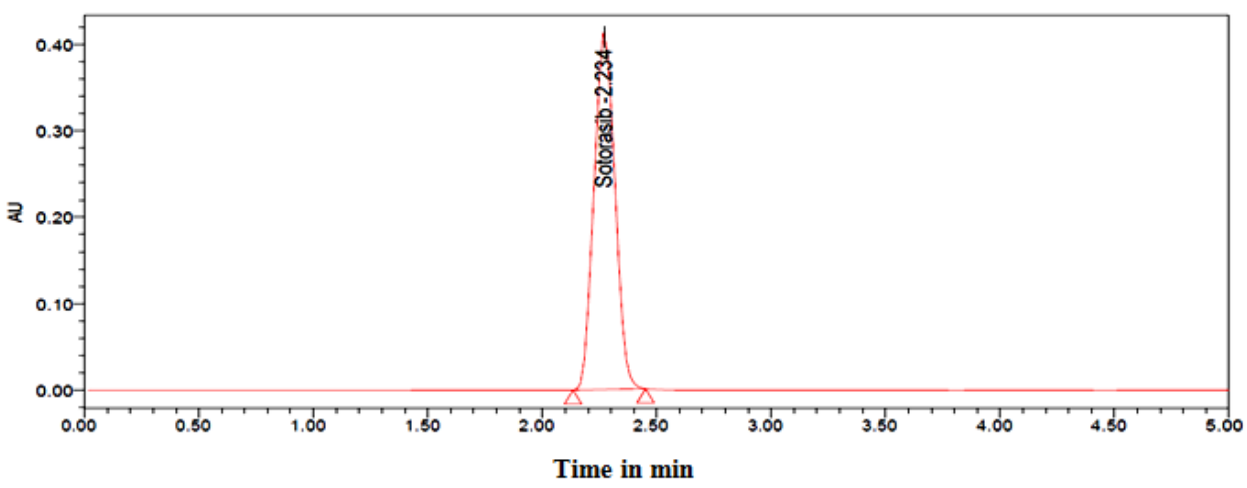

Fig. 5: Chromatogram of method precision

\section{Intermediate precision}

Separate instruments were used on different days, in different locations, for independent investigations into six different replicates of the standard solution. Mean RSD values have been calculated and determined from the peak regions. The following table shows the results. Sotorasib $(100 \mu \mathrm{g} / \mathrm{ml})$ was analysed on 6 different days with 6 different standards. Mean, standard deviation, and percent related standard deviation values were calculated from peak areas. Thus, it has been found that the current method yields very accurate results, with RSD values less than 2 percent and percent assay values near 100 percent. In table 5 [34] we can see the results.

Table 5: Inter-day outcomes of the accuracy of sotorasib

\begin{tabular}{llll}
\hline Sotorasib & & & \\
\hline S. No. & Conc. $(\boldsymbol{\mu g} / \mathbf{m l})$ & Area counts & \% assay as is \\
\hline 1 & 100 & 2658214 & 91.5 \\
2 & & 2613206 & 99.7 \\
3 & & 2615427 & 100.2 \\
4 & & 2626539 & 99.4 \\
5 & & 2604362 & 100.8 \\
6 & 0.765 & 2641488 & \\
Mean & 100.23 & & \\
SD & 0.787 & & \\
\hline
\end{tabular}

$\mathrm{n}=6$

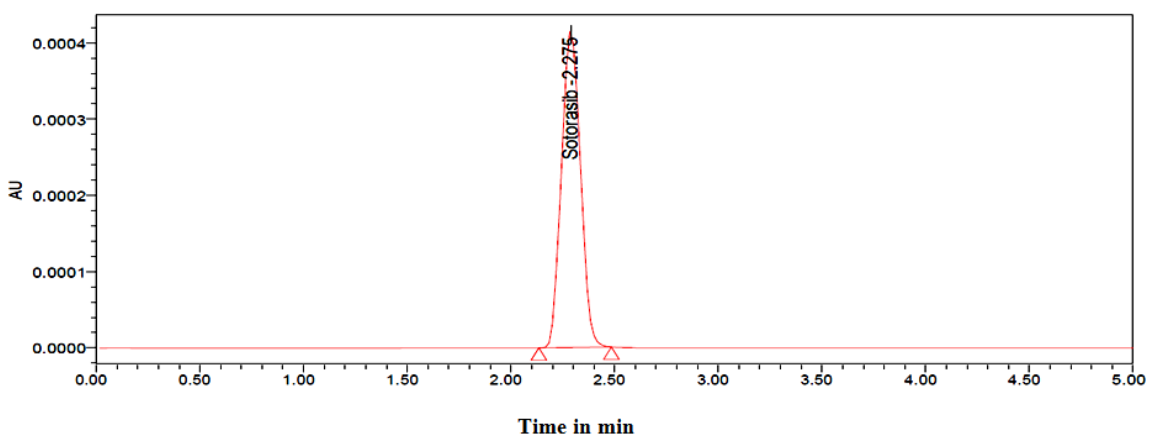

A

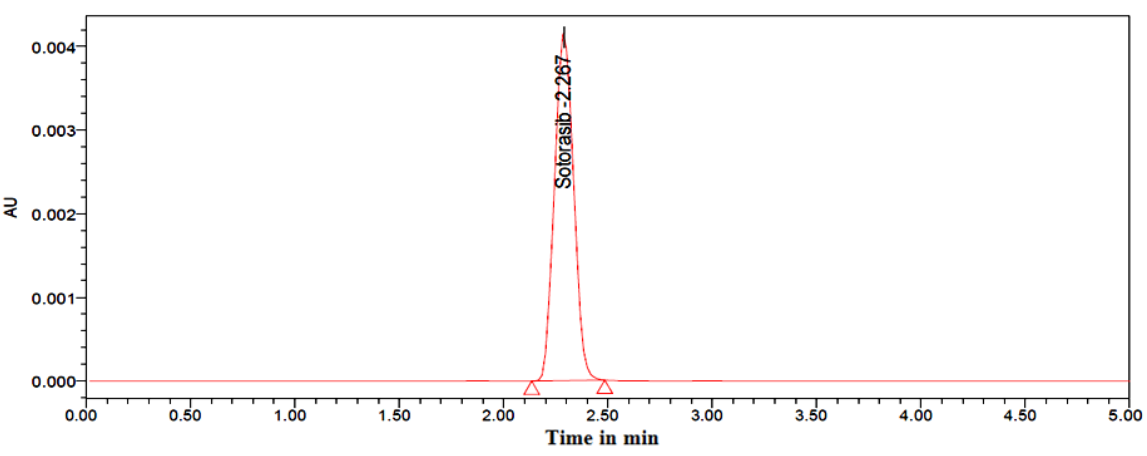

B

Fig. 6: Chromatogram of (A) LOD and (B) LOQ 


\section{LOD and LOQ}

The LOD concentration sotorasib was $0.125 \mu \mathrm{g} / \mathrm{ml}$ and $\mathrm{s} / \mathrm{n}$ values is 6 . The LOQ concentration for sotorasib was $0.413 \mu \mathrm{g} / \mathrm{ml}$ and their $\mathrm{s} / \mathrm{n}$ values are 25 . The method is validated as per the ICH guidelines [35].

\section{Robustness}

The design of the experiment was intentionally altered in order to test the robustness of the system. Examples of such changes include changing the flow rate, organic to inorganic ratio, and so on. The results were robust and tabulated in table 7 [36].

Table 6: LOD and LOQ for sotorasib

\begin{tabular}{llll}
\hline Sotorasib & & & \\
\hline LOD & & LOQ & \\
Concentration & $\mathrm{s} / \mathrm{n}$ & Concentration & $\mathrm{s} / \mathrm{n}$ \\
$0.125 \mu \mathrm{g} / \mathrm{ml}$ & 6 & $0.413 \mu \mathrm{g} / \mathrm{ml}$ & 25 \\
\hline
\end{tabular}

\section{Stability}

The solution was kept at room temperature and between 2 and 8 degrees Celsius for up to $24 \mathrm{~h}$ [37]. The experiment showed that the solutions remained stable for at least two days under room temperature and $2-8{ }^{\circ} \mathrm{C}$, Sotorasib drug has no effect. The following table 8 illustrates the results.

Table 7: Robustness data of sotorasib

\begin{tabular}{ll}
\hline Parameter name & \% RSD \\
\cline { 2 - 2 } & Sotorasib \\
\hline Flow minus $(0.8 \mathrm{ml} / \mathrm{min})$ & 0.63 \\
Flow plus $(1.2 \mathrm{ml} / \mathrm{min})$ & 0.51 \\
Organic minus $(63: 37)$ & 1.29 \\
Organic plus $(77: 23)$ & 0.88 \\
\hline
\end{tabular}

\section{Degradation studies}

Partial degradation of the drug was accomplished using various forced degradation conditions on the Sotorasib standard. Research has been carried out to see if the method works for degrading products $[38,39]$. Additionally, the studies describe the conditions under which the drug is unstable, providing further information so that appropriate precautions are taken during the process of formulation in order to avoid possible instabilities [40].

Table 8: Stability results of sotorasib

\begin{tabular}{lllll}
\hline Stability & Stability at RT & & Stability at 2-8 ${ }^{\circ} \mathbf{C}$ \\
\cline { 2 - 5 } & \% assay & \% of deviation & \% assay & \% of deviation \\
\hline Initial & 100 & 0.00 & 100 & 0.00 \\
$6 \mathrm{~h}$ & 99.6 & -0.40 & 99.5 & -0.50 \\
$12 \mathrm{~h}$ & 99.3 & -0.70 & 99.2 & -0.80 \\
$18 \mathrm{~h}$ & 98.7 & -1.30 & 96.2 & -3.80 \\
$24 \mathrm{~h}$ & 96 & -4.00 & 95.5 & -4.50 \\
\hline
\end{tabular}

\section{Acid degradation}

Acid degradation was done by using $1 \mathrm{~N} \mathrm{HCl}$ and $17.5 \%$ of Sotorasib degradation was observed.

\section{Alkali degradation}

Alkali degradation was done at $1 \mathrm{~N} \mathrm{NaOH}$ and $17.8 \%$ of Sotorasib degradation was observed.

\section{Peroxide degradation}

Peroxide degradation was performed with 30\% hydrogen peroxide and $18.6 \%$ Sotorasib degradation was observed.

\section{Reduction degradation}

Reduction degradation was performed with $30 \%$ sodium bi sulphate solution, $16.9 \%$ sotorasib degradation was observed.

\section{Thermal degradation}

In thermal degradation, the standard was degraded to $13.9 \%$ of Sotorasib.

All degradation results are tabulated in table 9.

Table 9: Forced degradation results of sotorasib

\begin{tabular}{lll}
\hline Degradation condition & Sotorasib & \\
\cline { 2 - 3 } & \% assay & \%Deg \\
\hline Acid degradation & 82.5 & 17.5 \\
Alkali degradation & 82.2 & 17.8 \\
Peroxide degradation & 81.4 & 18.6 \\
Reduction degradation & 83.1 & 16.9 \\
Thermal degradation & 86.1 & 13.9 \\
\hline
\end{tabular}

\section{CONCLUSION}

The developed method is accurate, precise and reliable for the analysis of Sotorasib in pharmaceutical formulations. This method was validated for linearity, accuracy, precision, robustness, forced degradation and stability of Sotorasib. The RSD values for all parameters were found to be less 2 , which indicates the validity of method and results obtained by this method are in fair agreement. Finally, this method can be used for better analysis of Sotorasib.

\section{ACKNOWLEDGEMENT}

The authors are thankful to Shree Icon Pharmaceutical Laboratories to complete this research work.

\section{AUTHORS CONTRIBUTIONS}

All the authors have contributed equally.

\section{CONFLICT OF INTERESTS}

\section{Declared none}

\section{REFERENCES}

1. Beumer JH, Chu E, Salamone SJ. Body-surface area-based chemotherapy dosing: appropriate in the $21^{\text {st }}$ century? J Clin Oncol 2012;30:3896-7.

2. Hunter RJ, Navo MA, Thaker PH, Bodurka DC, Wolf JK, Smith JA. Dosing chemotherapy in obese patients: actual versus assigned body surface area (BSA). Cancer Treat Rev 2009;35:69-78.

3. Safar AM, Spencer H, Su X, Coffey M, Cooney CA, Ratnasinghe LD, et al. Methylation profiling of archived non-small cell lung cancer: a promising prognostic system. Clin Cancer Res 2005;11:4400-5.

4. Reck M, Rodriguez Abreu D, Robinson AG, Hui R, Csoszi T, Fulop A, et al. Pembrolizumab versus chemotherapy for PD-L1-positive non-small-cell lung cancer. N Engl J Med 2016;375:1823-33.

5. Nagy A, Pongor LS, Szabo A, Santarpia M, Gyorffy B. KRAS driven expression signature has prognostic power superior to mutation status in non-small cell lung cancer. Int J Cancer 2017;140:930-7.

6. Guo W, Wu S, Liu J, Fang B. Identification of a small molecule with synthetic lethality for K-ras and protein kinase C iota. Cancer Res 2008;68:7403-8.

7. Canon J, Rex K, Saiki AY, Mohr C, Cooke K, Bagal D, et al. The clinical KRAS (G12C) inhibitor AMG 510 drives anti-tumor immunity. Nature 2019;575:217-23. 
8. Das S, Jayaratne R, Barrett KE. The role of ion transporters in the pathophysiology of infectious diarrhea. Cell Mol Gastroenterol Hepatol 2018;6:33-45.

9. Kumaraveloo, Sakthiaseelan K, Lunner Kolstrup, Christina. Agriculture and musculoskeletal disorders in low-and middleincome countries. J Agromedicine 2018;23:227-48.

10. Balaban CD, Yates BJ. What is nausea? A historical analysis of changing views. Auton Neurosci 2017;202:5-17.

11. Zielinski MR, Systrom DM, Rose NR. Fatigue, sleep, and autoimmune and related disorders. Front Immunol 2019;10:1827.

12. Davis JM, Alderson NL, Welsh RS. Serotonin and central nervous system fatigue: nutritional considerations. Am J Clin Nutr 2000;72:573S-8S

13. Wang HJ, Gao B, Zakhari S, Nagy LE. Inflammation in alcoholic liver disease. Annu Rev Nutr 2012;32:343-68.

14. Goldsobel AB, Chipps BE. Cough in the pediatric population. J Pediatr 2010;156:352-8

15. Wennerberg K, Rossman KL, Der CJ. The ras superfamily at a glance. J Cell Sci 2005;118:843-6.

16. Rocks O, Peyker A, Bastiaens PI. Spatio-temporal segregation of ras signals one ship, three anchors, many harbors. Curr Opin Cell Biol 2006;18:351-7.

17. Tammela, Tuomas, Sage, Julien. investigating tumor heterogeneity in mouse models. Annual Rev Cancer Biol 2020;4:99-119.

18. Bond Smith G, Banga N, Hammond TM, Imber CJ. Pancreatic adenocarcinoma. Br Med J 2012;344:e2476.

19. Juul JS, Hornung N, Andersen B, Laurberg S, Olesen F, Vedsted $P$. The value of using the faecal immunochemical test in general practice on patients presenting with non-alarm symptoms of colorectal cancer. Br J Cancer 2018;119:471-9.

20. Guinney J, Dienstmann R. The consensus molecular subtypes of colorectal cancer. Nat Med 2015;21:1350-6.

21. Karki L. Review of FDA law related to pharmaceuticals: the hatch-waxman act, regulatory amendments and implications for drug patent enforcement. J Pat Off Soc 2005;87:602-20.

22. Postow MA, Callahan MK, Wolchok JD. immune checkpoint blockade in cancer therapy. J Clin Oncol 2015;33:1974-82.

23. Dunn GP, Koebel CM, Schreiber RD. Interferons, immunity and cancer immunoediting. Nat Rev Immunol 2006;6:836-48.

24. Johnstone TC, Park GY, Lippard SJ. Understanding and improving platinum anticancer drugsphenanthriplatin. Anticancer Res 2014;34:471-6.

25. Oun R, Moussa YE, Wheate NJ. The side effects of platinumbased chemotherapy drugs: a review for chemists. Dalton Trans 2018;47:6645-53.

26. Bhavani P, Prasada Rao K, Mohan S. Novel validated reversedphase high-performance liquid chromatography method for determination of glucosamine, diacerein, and methyl sulfonyl methane in micro-sample rat plasma and its application to pharmacokinetic and dissolution studies. Asian J Pharm Clin Res 2020;13:50-63.
27. Mukta D Naykode, Durgacharan A Bhagwat, Swapnil D Jadhav, Harinath N. Analytical and bioanalytical method for quantification of pure azilsartan, not its salt by RP-HPLC. Res J Pharm Tech 2017; 10:708-14

28. Mayanka Singh, Manoj Charde, Rajesh Shukla, Rita MC Determination of calcipotriene in calcipotriene cream $0.05 \%$ w/w by RP-HPLC method development and validation. Res J Pharm Tech 2011;4:1219-23.

29. Malathi S, Arunadevi N. Development and validation of stability-indicating simultaneous estimation of metformin and alogliptin in tablets by high-performance thin-layer chromatography. Int J Pharm Pharm Sci 2020;12:68-73.

30. Manoranjani M. A study of method development, validation and forced degradation for simultaneous quantification of cisplatin and fluorouracil in bulk and pharmaceutical dosage form by RP-HPLC. J Pharm Sci Rev 2021;13:155-61.

31. Prasada Rao PTSRK. A study of method development and validation for simultaneous estimation of pemetrexed and cisplatin using RP-HPLC. J Pharm Sci Rev 2021;13:143-8.

32. Satyadev TNVSS. A new selective separation method development and validation of cabozantinib and nivolumab using HPLC. J Pharm Sci Rev 2021;13:188-92.

33. David Raju M. Development and validation of HPLC method for the determination of lasmiditan drug in bulk and tablet dosage form. J Pharm Sci Rev 2021;13:170-3.

34. Shanmugasundaram P, Kamarapu SK. RP-HPLC method for the simultaneous estimation and validation of amlodipine besylate and atenolol in bulk and tablet dosage form in biorelevant dissolution medium (Fassif). Res J Pharm Tech 2017;10:3379-85.

35. International conference on harmonization. ICH harmonized tripartite guideline. Validation of analytical procedures: Text and methodology Q2(R1); 2005.

36. Syed Rafi, Kantipudi Rambabu. Stability indicating validated HPLC method for the determination of aceclofenac and misoprostol in bulk and pharmaceutical formulation. Int J Res Pharm Sci 2020;11:7848-53.

37. Swati K, Abhishek P, Sushank S, Bothiraja C, Atmaram P. Highperformance liquid chromatography for the simultaneous estimation of cefoperazone and sulbactam in rat plasma and its importance in therapeutic drug monitoring. Int J Pharm Pharm Sci 2020;12:92-7.

38. Rajakumari R, Sreenivasa Rao S. Stress degradation studies and development of a validated RP-HPLC method for determination of tiagabine in presence of its degradation products. Int J Pharm Pharm Sci 2016;8:230-6.

39. Charu Pandya P, Sadhana Rajput J. Development and validation of stability-indicating method RP-HPLC method of acotiamide. Int J Pharm Pharm Sci 2018;10:1-8.

40. Birva Athavia A, Zarna Dedania R. Stability indicating HPLC method for determination of vilazodone hydrochloride. Int J Curr Pharm Res 2017;9:123-9. 